\title{
Effects of lower thoracic sympathicotomy on plantar hyperhidrosis
}

\author{
Seong Cheol Jeong ${ }^{1}$, Jae Jun Kim ${ }^{1}$, In Sub Kim ${ }^{1}$, Yong Hwan Kim ${ }^{1}$, Jung Wook Han ${ }^{1}$, Seok Whan Moon ${ }^{2}$ \\ ${ }^{1}$ Department of Thoracic and Cardiovascular Surgery, Uijeongbu St. Mary's Hospital, College of Medicine, The Catholic University of Korea, \\ Gyeonggi-do, Republic of Korea; ${ }^{2}$ Department of Thoracic and Cardiovascular Surgery, Seoul St. Mary's Hospital, College of Medicine, The \\ Catholic University of Korea, Seoul, Republic of Korea \\ Contributions: (I) Conception and design: SC Jeong, JJ Kim; (II) Administrative support: JJ Kim; (III) Provision of study materials and patients: YH \\ Kim, JW Han; (IV) Data collection and assembly: IS Kim, SW Moon; (V) Data analysis and interpretation: JJ Kim, SC Jeong; (VI) Manuscript \\ writing: All authors; (VII) Final approval of manuscript: All authors. \\ Correspondence to: Jae Jun Kim, MD, PhD. Department of Thoracic and Cardiovascular Surgery, Uijeongbu St. Mary's Hospital, College of Medicine, \\ The Catholic University of Korea, Geumo-dong, Uijeongbu, Gyeonggi-do 480-717, Republic of Korea. Email: medkjj@hanmail.net.
}

Background: The purpose of this study was to investigate whether performing lower thoracic sympathicotomy (LTS) from T10 to T12 affects plantar hyperhidrosis in patients with palmo-plantar (PP) or palmo-axillary-plantar (PAP) hyperhidrosis.

Methods: Between January 2015 and January 2020, all consecutive patients with primary hyperhidrosis who underwent bilateral thoracoscopic sympathicotomy and met the inclusion criteria were included. Sympathicotomy was performed using one of the following two methods: the conventional upper thoracic $v s$. expanded thoracic sympathicotomy. In the expanded thoracic sympathicotomy, we expanded the level of sympathicotomy ranging from R5 to R12 in addition to the conventional upper thoracic sympathicotomy (R3 or R4). In cases of the expanded thoracic sympathicotomy, we defined the LTS as a sympathicotomy of the levels ranging from R10 to R12, which are related to plantar hyperhidrosis.

Results: A total of 103 subjects with PP (71 cases) or PAP (32 cases) hyperhidrosis were included. Palmar or axillary hyperhidrosis in all patients were alleviated after sympathicotomy. There was no difference in sweating decrease or $\mathrm{CH}$ according to the hyperhidrosis types or sympathicotomy techniques. In addition, no-LTS was performed in 77 cases and LTS was performed in 26 cases. In the no-LTS group, there were 65 and 12 cases of low and high degrees of $\mathrm{CH}$, respectively. In the LTS group, there were 22 and four cases of low and high degrees of $\mathrm{CH}$, respectively. There was no significant difference in $\mathrm{CH}$ between the no-LTS and LTS groups $(\mathrm{P}=0.981)$. Improvement in plantar hyperhidrosis in the no-LTS group was observed in 29 of 77 cases, while improvement in plantar hyperhidrosis in the LTS group was observed in 16 of 26 cases. The addition of LTS lead to significant improvement in plantar hyperhidrosis $(\mathrm{P}=0.034)$.

Conclusions: Performing LTS is a safe and feasible procedure that improved plantar sweating more so than it did in cases that did not undergo LTS. Therefore, we cautiously suggest that adding LTS helps in the treatment of plantar hyperhidrosis combined with palmar hyperhidrosis. Further studies on LTS are needed to validate these findings and will be helpful in establishing management guidelines.

Keywords: Plantar hyperhidrosis, thoracic sympathicotomy

Submitted Jul 14, 2020. Accepted for publication Nov 27, 2020.

doi: $10.21037 /$ jtd-20-2437

View this article at: http://dx.doi.org/10.21037/jtd-20-2437

\section{Introduction}

Primary hyperhidrosis $(\mathrm{PH})$ is a disorder characterized by excessive and uncontrollable sweating, which typically involves the craniofacial regions, palms, axillae, and soles
$(1,2)$. Eccrine sweat glands are considered to be associated with $\mathrm{PH}$ (1). Many patients suffer from $\mathrm{PH}$, which adversely affects quality of life (3). Recently, thoracoscopic thoracic sympathetic blockage has been accepted as the most 
effective treatment modality for $\mathrm{PH}$ that is refractory to conservative treatment $(1,3,4)$. Usually, the upper thoracic sympathetic levels ranging from $\mathrm{T} 2$ to $\mathrm{T} 5$ by various methods are blocked according to the hyperhidrosis type, patient condition, and surgeon preference (5-7). Although palmar hyperhidrosis is a predominant form of $\mathrm{PH}$, plantar hyperhidrosis also occurs in $>50 \%$ of cases $(1,8,9)$. When upper thoracic sympathetic blockage is performed for palmar hyperhidrosis accompanied by plantar hyperhidrosis, there is sometimes an improvement in plantar hyperhidrosis (10-12). Many studies have investigated the effect of upper thoracic sympathectomy on plantar hyperhidrosis $(4,7,9,13,14)$. However, the results vary across studies for unclear reasons $(4,12-15)$. The lower thoracic sympathetic nerves from T10 to 12 innervate the legs and feet $(16,17)$. The effect of lower thoracic sympathetic blockage from T10 to T12 on plantar hyperhidrosis remains unknown. There is no consensus regarding the management of plantar hyperhidrosis combined with palmar hyperhidrosis $(8,11$ $13,18,19)$. It is unknown whether thoracic sympathectomy alone is sufficient in patients who have both palmar and plantar hyperhidrosis $(8,11-13,18,19)$. However, this is an important question to address, as plantar hyperhidrosis is frequently accompanied by other forms of $\mathrm{PH}(8,20)$. Therefore, the aim of the present study was to investigate whether adding lower thoracic sympathicotomy (LTS) from T10 to T12 improves plantar hyperhidrosis in patients with palmo-plantar (PP) or palmo-axillary-plantar (PAP) hyperhidrosis. We present the following article in accordance with the STROBE reporting checklist (available at http://dx.doi.org/10.21037/jtd-20-2437).

\section{Methods}

\section{Study participants and procedures for sympathetic blockage}

From January 2015 to January 2020, all consecutive patients with $\mathrm{PH}$ who underwent bilateral thoracoscopic sympathicotomy and met the inclusion criteria were included (Figure 1). The inclusion criteria for this study were as follows: (I) PP or PAP hyperhidrosis; (II) no previous sympathetic blockage; (III) no further treatment of plantar hyperhidrosis after sympathicotomy; (IV) no systemic disease related to $\mathrm{PH}$; and $(\mathrm{V})$ response to the telephone questionnaire surveys. The medical records were retrospectively reviewed, Telephone questionnaire surveys were also performed to collect clinical data on subjects, hyperhidrosis characteristics, operative procedures, and postoperative outcomes. The telephone survey addressed sweating symptoms, such as decrease or recurrence of sweating in the affected regions and compensatory hyperhidrosis $(\mathrm{CH})$ (degree, localization, time of onset) after sympathicotomy. The degree of sweating after sympathicotomy was characterized by a decrease (improvement) or failure (no change or recurrence of sweating). $\mathrm{CH}$ was characterized by low (none and mild) or high (moderate and severe) degrees. Sympathicotomy was performed using one of the following two methods: the conventional upper thoracic vs. expanded thoracic sympathicotomy. During conventional upper thoracic sympathicotomy, R3 or R4 sympathicotomy were performed using electrocauterization. When the level of sympathicotomy included both R3 and R4, we considered these cases as R3 sympathicotomy. In the cases of expanded thoracic sympathicotomy, patients were put under general anesthesia with single lumen endotracheal anesthesia in the prone position, underwent a 5 -mm, two-port endoscopic sympathicotomy using a $\mathrm{CO}_{2}$ gas insufflation via the sixth intercostal space on the mid-axillary line and the seventh intercostal space on the post-axillary line (2). We expanded the level of sympathicotomy ranging from $\mathrm{R} 5$ to R12 in addition to the conventional upper thoracic sympathicotomy (level of R3 or R4). In cases of expanded thoracic sympathicotomy, we defined lower thoracic sympathicotomy (LTS) as sympathicotomy of R10 through R12 related to plantar hyperhidrosis. All the patients underwent sympathicotomy using the thoracoscopic technique. Gustatory hyperhidrosis was not evaluated. The initial postoperative outcomes were routinely evaluated one month after sympathicotomy, and all the telephone surveys were performed in June 2020.

\section{Statistical analysis}

All results are presented as means \pm SDs. Continuous independent variables were analyzed using Student's t tests, while categorical variables were analyzed using the chisquare test. The results were analyzed using the Statistical Package of Social Sciences version 22.0 (SPSS, IBM Corp, NY, USA). P values $<0.05$ were considered statistically significantly.

\section{Ethical statement}

Informed consents were given before study and this study was approved by the Uijeongbu Saint Mary's Hospital 


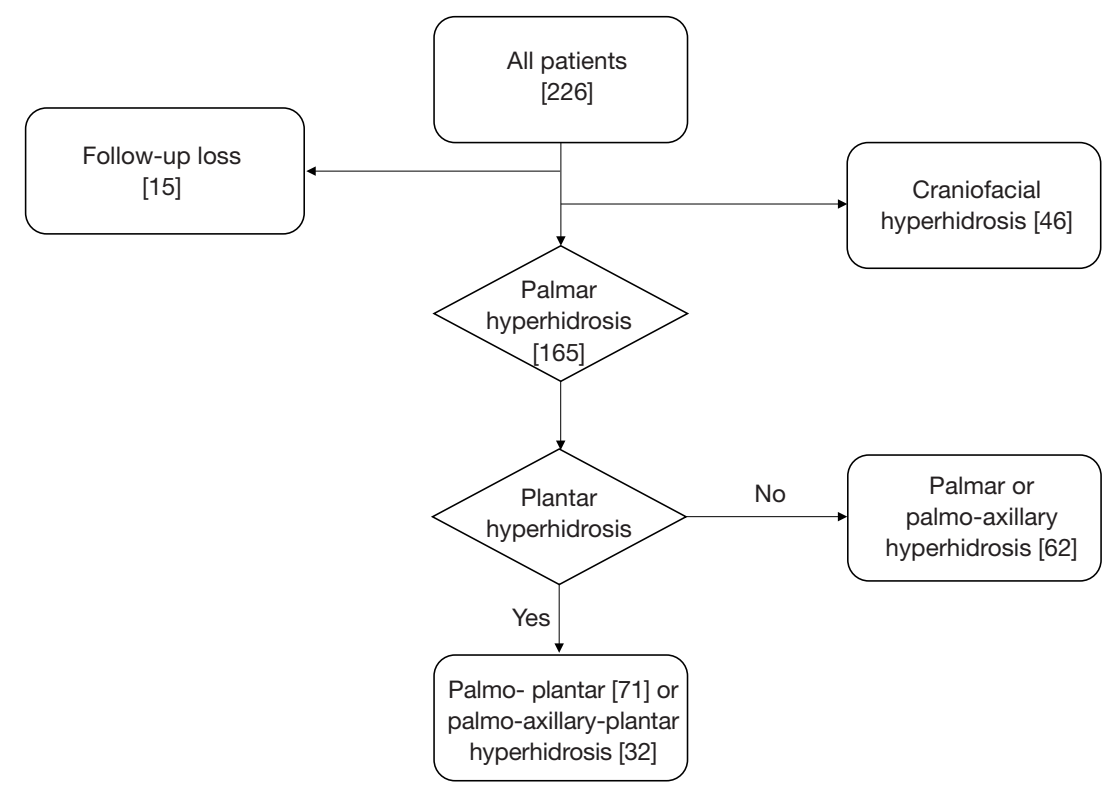

Figure 1 Flowchart of patient selection.

Ethics Committee (Approval number: UC20RISI0108). We confirm that the study conformed to the provisions of the Declaration of Helsinki (as revised in 2013).

\section{Results}

A total of 103 subjects with $\mathrm{PH}$ were included in the study. The mean age of the study subjects was $22.1( \pm 9.0)$ years at the time of surgery and the mean duration of observation was $33.8( \pm 18.1)$ months. Sixty-four of participants were male, and 39 were female. There were 71 cases of PP and 32 cases of PAP hyperhidrosis. We divided the subjects into two groups according to the addition of LTS (no lower thoracic sympathicotomy (no-LTS) vs. lower thoracic sympathicotomy (LTS) groups). LTS was performed in 26 of 103 cases. There were no postoperative mortalities or major complications. The overall clinical characteristics of the study subjects are presented in Table 1.

\section{Sweating decrease in the hands or axillae according to the byperhidrosis type and the techniques of sympatbicotomy}

R3 or R4 sympathicotomy with or without LTS were performed for hyperhidrosis. Palmar or axillary hyperhidrosis in all patients were completely alleviated after sympathicotomy. There were no cases of recurrence during the observation periods. Therefore, there was no difference in sweating decrease according to the hyperhidrosis type or the sympathicotomy technique (Table 1).

\section{CH after sympathicotomy according to the hyperbidrosis type and the sympatbicotomy techniques (level of sympatbicotomy and LTS)}

We classified the degree of $\mathrm{CH}$ into low (none and mild) and high (moderate and severe) degrees. In PP hyperhidrosis, there were 63 and 8 cases of low and high degree of $\mathrm{CH}$, respectively. In PAP hyperhidrosis, there were 24 and 8 cases of low and high degree of $\mathrm{CH}$, respectively. There was no significant difference in $\mathrm{CH}$ according to the hyperhidrosis type (Table 1). In R3 sympathicotomy, there were 62 and 12 cases of low and high degree of $\mathrm{CH}$, respectively. In $\mathrm{R} 4$ sympathicotomy, there were 25 and 4 cases of low and high degree of $\mathrm{CH}$, respectively. There was no significant difference in $\mathrm{CH}$ between $\mathrm{R} 3$ and $\mathrm{R} 4$ sympathicotomy $(\mathrm{P}=0.760)$ (Table 2). In addition, LTS was performed in 26 cases, while it was not performed in 77 cases. In case in which LTS was not performed, there were 65 and 22 cases of low and high degree of $\mathrm{CH}$, respectively. In cases in which LTS was performed, there were 12 and 4 cases of low and high degree of $\mathrm{CH}$, respectively. There was no significant difference in $\mathrm{CH}$ between the no-LTS and LTS groups $(\mathrm{P}=0.981)$ (Table 2). 
Table 1 The overall clinical characteristics of the study subjects

\begin{tabular}{|c|c|c|c|}
\hline Variables & \multicolumn{2}{|c|}{ Hyperhidrosis } & $P$ value \\
\hline Age (year) & $21.5( \pm 8.8)$ & $23.3( \pm 9.6)$ & 0.358 \\
\hline Sex & & & 0.088 \\
\hline Male & 48 & 16 & \\
\hline Level of sympathicotomy & & & 0.346 \\
\hline R3 & 53 & 21 & \\
\hline R4 & 18 & 11 & \\
\hline Sympathicotomy technique & & & 0.346 \\
\hline Sweating decrease in the hands or axillae & & & N/A \\
\hline Decrease & 71 & 32 & \\
\hline Failure & 0 & 0 & \\
\hline Compensatory Hyperhidrosis & & & 0.075 \\
\hline Low degree & 63 & 24 & \\
\hline High degree & 8 & 8 & \\
\hline
\end{tabular}

LTS, lower thoracic sympathicotomy.

Table 2 Compensatory hyperhidrosis after sympathicotomy according to the techniques of sympathicotomy

\begin{tabular}{|c|c|c|c|c|}
\hline Technique of sympathicotomy & & \multicolumn{2}{|c|}{ Compensatory hyperhidrosis } & $P$ value \\
\hline \multirow[t]{2}{*}{ Level } & $\mathrm{R} 3$ & 62 & 12 & 0.760 \\
\hline & $\mathrm{R} 4$ & 25 & 4 & \\
\hline Lower thoracic sympathicotomy & No & 65 & 12 & 0.981 \\
\hline
\end{tabular}

Plantar hyperbidrosis after sympatbicotomy according to the hyperbidrosis type and the sympathicotomy technique

We did not add LTS in cases of R4 sympathicotomy. Therefore, we did not analyze the effects of LTS on plantar hyperhidrosis according to the sympathicotomy levels (R3 vs. R4). Improvement of plantar hyperhidrosis in the noLTS group was observed in 29 of 77 cases. Improvement of plantar hyperhidrosis in the LTS group was observed in 16 of 26 cases. The addition of LTS led to a significant improvement in plantar hyperhidrosis $(\mathrm{P}=0.034)$ (Table 3).

\section{Discussions}

Although palmar hyperhidrosis is a the most common form of $\mathrm{PH}$, plantar hyperhidrosis frequently accompanies palmar hyperhidrosis $(1,8,9)$. There is no consensus regarding the management of plantar hyperhidrosis combined with palmar hyperhidrosis $(8,11-13,18,19)$. The leg and foot are innervated by the efferent sudomotor fibers coming from the ipsilateral segments from T10 to L4 $(16,17)$. Recently, lumbar sympathectomy is accepted as an effective treatment for plantar hyperhidrosis (16-18,21). 
Table 3 Plantar hyperhidrosis after thoracic sympathicotomy according the techniques of sympathicotomy

\begin{tabular}{lccc}
\hline \multirow{2}{*}{ Technique of sympathicotomy } & \multicolumn{2}{c}{ Plantar hyperhidrosis } \\
\cline { 3 - 5 } & & Improvement & Failure \\
\hline Lower thoracic sympathicotomy & No & 29 & 48 \\
& Yes & 16 & 10 \\
\hline
\end{tabular}

However, the chief complaint in patients with $\mathrm{PH}$ is usually palmar hyperhidrosis. In addition, thoracic surgeons are not typically familiar with the lumbar and retroperitoneal areas. Furthermore, lumbar sympathectomy is a relatively difficult procedure with a higher complication rate than that of thoracic sympathectomy. Although the reasons are not clear, upper thoracic sympathectomy has been shown to variably decrease plantar hyperhidrosis. Therefore, upper thoracic sympathectomy alone is usually performed in patients with palmar hyperhidrosis combined with plantar hyperhidrosis $(18,19,22)$. Although T10-T12 thoracic sympathetic nerves are related to plantar sympathetic innervation, the effect of thoracic sympathectomy from T10 to T12 on plantar hyperhidrosis remains unknown (16). To the best of our knowledge, this study is the first to evaluate the effect of LTS from T10 to T12 on plantar hyperhidrosis.

Because the leg and foot are innervated by efferent sudomotor fibers coming from the T10-L4 ipsilateral segments, we assumed that LTS from T10 to T12 would improve plantar hyperhidrosis. It is relatively easy to add LTS on T10-12 during the conventional upper thoracic sympathectomy in patients with both palmar and plantar hyperhidrosis. In addition, it is important to investigate the effect of LTS on plantar hyperhidrosis. Therefore, we investigated whether LTS (T10-T12) in patients with PP or PAP hyperhidrosis affects plantar hyperhidrosis. Previously, our group published the paper "New Sympathicotomy for Prevention of Severe Compensatory Hyperhidrosis in Patients With Primary Hyperhidrosis" (2). In that study, we performed full-expanded sympathicotomy, which expanded the levels of sympathicotomy beyond R8 to the R9 through R12. We found LTS to be a safe and feasible procedure.

This study included 103 patients who underwent bilateral thoracoscopic sympathicotomy for PP or PAP hyperhidrosis. All the patients experienced an improvement in sweating in the hands or axillae after sympathicotomy. The decrease in sweating and $\mathrm{CH}$ did not differ according to the type of hyperhidrosis or the sympathicotomy technique. There was improvement in plantar hyperhidrosis in 29 of 77 patients in the no-LTS group, and in 16 of 26 patients in the LTS group. Therefore, adding LTS provided a significant improvement in plantar hyperhidrosis compared to cases in which LTS was not performed (no-LTS group). It is well established that R3 sympathicotomy is more effective in treating palmar hyperhidrosis than is R4 sympathicotomy, because R3 sympathicotomy provides a wider sympathetic blockage to the upper limbs than R4 one (16). Although sympathectomy on T10-T12 cannot block all of the sudomotor nerves that innervate the leg and foot, their sympathetic blockage decreased sweating (compared to cases in which LTS was not performed), which supported our hypothesis (17). It remains unclear why upper thoracic sympathectomy can improve plantar hyperhidrosis (4). We believe that the association between the upper and lower thoracic sympathetic nerves may explain the effect of upper thoracic sympathectomy on plantar hyperhidrosis. Although adding LTS improved plantar hyperhidrosis, the addition of LTS alone is not sufficient treatment for plantar hyperhidrosis because it does not offer full sympathetic blockage $(9,14)$.

This study has several limitations. This was a singlecentered, retrospective study with a small number of subjects. We did not include any objective measures of sweating, and the subjects were not randomized according to sympathicotomy or hyperhidrosis types. In addition, there was no defined sympathetic chain at the T11-T12 levels in some cases, in which blind electrocauterization was performed. Despite these limitations, we strictly applied our inclusion criteria to reduce bias.

\section{Conclusions}

Adding LTS is a safe and feasible procedure that improves sweating control in patients with plantar hyperhidrosis without any major postoperative complications. We cautiously suggest that LTS is helpful to reduce additional treatment for plantar hyperhidrosis in patients with concurrent palmar hyperhidrosis. Regardless, further studies on LTS are needed to substantiate our findings and help to establish management guidelines. Studies on LTS will 
also enhance our understanding of the association between palmar and plantar hyperhidrosis, the pathophysiology of plantar hyperhidrosis, and the mechanisms by which plantar sweating decreases after upper thoracic sympathectomy.

\section{Acknowledgments}

Funding: None.

\section{Footnote}

Reporting Checklist: The authors have completed the STROBE reporting checklist. Available at http://dx.doi. org/10.21037/jtd-20-2437

Data Sharing Statement: Available at http://dx.doi. org/10.21037/jtd-20-2437

Conflicts of Interest: All authors have completed the ICMJE uniform disclosure form (available at http://dx.doi. org/10.21037/jtd-20-2437). The authors have no conflicts of interest to declare.

Ethical Statement: The authors are accountable for all aspects of this work. The authors ensure that questions related to the accuracy or integrity of any part of the work are appropriately investigated and resolved. Informed consents were given before study and this study was approved by the Uijeongbu Saint Mary's Hospital Ethics Committee (Approval number: UC20RISI0108). We confirm that the study conformed to the provisions of the Declaration of Helsinki (as revised in 2013).

Open Access Statement: This is an Open Access article distributed in accordance with the Creative Commons Attribution-NonCommercial-NoDerivs 4.0 International License (CC BY-NC-ND 4.0), which permits the noncommercial replication and distribution of the article with the strict proviso that no changes or edits are made and the original work is properly cited (including links to both the formal publication through the relevant DOI and the license). See: https://creativecommons.org/licenses/by-nc-nd/4.0/.

\section{References}

1. Nawrocki S, Cha J. The etiology, diagnosis, and management of hyperhidrosis: A comprehensive review: Etiology and clinical work-up. J Am Acad Dermatol
2019;81:657-66.

2. Han JW, Kim JJ, Kim YH, et al. New sympathicotomy for prevention of severe compensatory hyperhidrosis in patients with primary hyperhidrosis. J Thorac Dis 2020;12:765-72.

3. Wolosker N, Kauffman P, de Campos JRM, et al. Longterm results of the treatment of primary hyperhidrosis with oxybutynin: follow-up of 1,658 cases. Int J Dermatol 2020;59:709-15.

4. Paliogiannis P, Scognamillo F, Attene F, et al. Impact of transthoracic endoscopic sympathectomy on plantar hyperhidrosis. Ann Ital Chir 2014;85:114-9.

5. Kargi AB. Plantar Sweating as an Indicator of Lower Risk of Compensatory Sweating after Thoracic Sympathectomy. Thorac Cardiovasc Surg 2017;65:479-83.

6. Karamustafaoglu YA, Kuzucuoglu M, Yanik F, et al. 3-year follow-up after uniportal thoracoscopic sympathicotomy for hyperhidrosis: undesirable side effects. J Laparoendosc Adv Surg Tech A 2014;24:782-5.

7. Gorur R, Yiyit N, Yildizhan A, et al. Is T3 and T6 sympathetic clipping more effective in primary palmoplantar hyperhydrosis? Thorac Cardiovasc Surg 2011;59:357-9.

8. Vlahovic TC. Plantar Hyperhidrosis: An Overview. Clin Podiatr Med Surg 2016;33:441-51.

9. Urena A, Ramos R, Masuet C, et al. An assessment of plantar hyperhidrosis after endoscopic thoracic sympathicolysis. Eur J Cardiothorac Surg 2009;36:360-3.

10. Singh S, Kaur S, Wilson P. Early experience with endoscopic lumbar sympathectomy for plantar hyperhidrosis. Asian J Endosc Surg 2016;9:128-34.

11. Costa Jr AS, Leao LE, Succi JE, et al. Randomized trial - oxybutynin for treatment of persistent plantar hyperhidrosis in women after sympathectomy. Clinics 2014;69:101-5.

12. Wolosker N, Ishy A, Yazbek G, et al. Objective evaluation of plantar hyperhidrosis after sympathectomy. Clinics 2013;68:311-5.

13. Xiao P, Liu A, Liu W. Effect of T4 thoracoscopic sympathectomy on plantar hyperhidrosis in patients with primary palmoplantar hyperhidrosis. Zhong Nan Da Xue Xue Bao Yi Xue Ban 2016;41:300-4.

14. Tetteh HA, Groth SS, Kast T, et al. Primary palmoplantar hyperhidrosis and thoracoscopic sympathectomy: a new objective assessment method. Ann Thorac Surg 2009;87:267-74; discussion 274-5.

15. Youssef T, Soliman M. Unilateral sequential endoscopic thoracic sympathectomy for palmar hyperhidrosis: 
a proposed technique to overcome compensatory hyperhidrosis and improve plantar hyperhidrosis. J Laparoendosc Adv Surg Tech A 2015;25:370-4.

16. Schick CH. Pathophysiology of Hyperhidrosis. Thorac Surg Clin 2016;26:389-93.

17. Dellon AL, Hoke A, Williams EH, et al. The sympathetic innervation of the human foot. Plast Reconstr Surg 2012;129:905-9.

18. Yun SW, Kim YS, Lee Y, et al. Outcome of Limited Video-Assisted Lumbar Sympathetic Block for Plantar Hyperhidrosis Using Clipping Method. J Laparoendosc Adv Surg Tech A 2017;27:36-42.

19. Rieger R, Loureiro Mde P, Pedevilla S, et al. Endoscopic lumbar sympathectomy following thoracic sympathectomy in patients with palmoplantar hyperhidrosis. World J Surg 2011;35:49-53.

20. de Lima AG, Das-Neves-Pereira JC, de Campos JR, et al. Factors affecting long-term satisfaction after thoracic sympathectomy for palmar and plantar hyperhidrosis. Is the sudomotor reflex the only villain? Interact Cardiovasc Thorac Surg 2011;12:554-7.

21. Lima SO, Santos RS, Moura AMM, et al. A systematic review and meta-analysis to evaluate the efficacy of lumbar sympathectomy for plantar hyperhidrosis. Int J Dermatol 2019;58:982-6.

22. Singh S, Kaur S, Wilson P. Plantar hyperhidrosis: A review of current management. J Dermatolog Treat 2016;27:556-61.
Cite this article as: Jeong SC, Kim JJ, Kim IS, Kim YH, Han JW, Moon SW. Effects of lower thoracic sympathicotomy on plantar hyperhidrosis. J Thorac Dis 2021;13(2):664-670. doi: 10.21037/jtd20-2437 